\title{
Effect of Microstructure on the Resilience of Silicon Carbide to Palladium Attack
}

\author{
Eddie López-Honorato, Kun Fu, Philippa Jill Meadows, Jun Tan, and Ping Xiao ${ }^{\dagger}$ \\ Materials Science Centre, School of Materials, University of Manchester, Grosvenor St., Manchester M1 7HS, UK
}

\begin{abstract}
The $\mathrm{Pd} /$ silicon carbide $(\mathrm{SiC})$ reaction rate in tristructural isotropic (TRISO)-coated fuel particles has been studied. We have shown that it is possible to reduce the attack by palladium significantly by controlling the $\mathrm{SiC}$ microstructure. Large grain sizes as well as high coating rates did not increase the attack by $\mathrm{Pd}$ as previously thought. The activation energy for the $\mathrm{Pd} / \mathrm{SiC}$ reaction obtained for the optimized $\mathrm{SiC}$ coatings, $337 \mathrm{~kJ} / \mathrm{mol}$, is almost twice as high as for standard coatings $(\sim 160-190 \mathrm{~kJ} / \mathrm{mol})$ and five times higher than for porous samples $(67 \mathrm{~kJ} / \mathrm{mol})$. An increase of the (111) texture component and the characteristics of the grain boundaries are suggested as possible reasons for reduction of the $\mathrm{Pd} / \mathrm{SiC}$ reaction.
\end{abstract}

\section{Introduction}

$\mathrm{T}$ HE tristructural isotropic (TRISO)-coated fuel particle for the high-temperature reactor creates a small fissionproduct-containment vessel by coating a uranium kernel of around $500 \mu \mathrm{m}$ diameter with a low-density pyrolytic carbon (buffer layer), an inner dense pyrolytic carbon, a silicon carbide (SiC) layer, and an outer pyrolytic carbon coating. ${ }^{1}$ The $\mathrm{SiC}$ coating is the main diffusion barrier and provides the mechanical stability to the fuel, therefore its structural integrity is vital to the safe enclosure of all fission products. Palladium has been identified as the primary fission product causing $\mathrm{SiC}$ degradation because it readily reacts with $\mathrm{SiC}$ forming palladium silicides and releasing free carbon. ${ }^{2-7}$ It has been observed that the $\mathrm{Pd} / \mathrm{SiC}$ interaction can reach several micrometers, i.e. $11 \mu \mathrm{m}$, thus creating weak points in the structure of $\mathrm{SiC}$ that could seriously reduce the strength of this material. This type of reaction also limits the use of $\mathrm{SiC}$ as a coating material for the very high temperature reactor because the higher temperatures (up to $1250^{\circ} \mathrm{C}$ ) and burn-ups (number of atoms that undergo a fission reaction; ; up to $20 \%$ fission per initial metal atom) would accelerate the degradation of $\mathrm{SiC}^{8}$

In the past, a number of studies have been performed trying to understand the release of palladium from the kernel and its interaction with $\mathrm{SiC}$, finding that temperature of the fuel was the major factor affecting the $\mathrm{Pd} / \mathrm{SiC}$ reaction rate. Few studies have been conducted to examine how the microstructure of $\mathrm{SiC}$ affects the reaction between $\mathrm{SiC}$ and $\mathrm{Pd} .^{2-5,7,9-11}$ It was observed that the resultant microstructural changes introduced by increasing the coating rate from 0.15 to $1 \mu \mathrm{m} / \mathrm{min}$ (all samples were deposited at $1500^{\circ} \mathrm{C}$ with only methyltrichlorosilane (MTS) as precursor) resulted in an increase of the reaction rate from $\sim 2 \times 10^{-3}$ to $\sim 2 \times 10^{-2} \mu \mathrm{m} / \mathrm{h}$. ${ }^{2}$ The deposition temperature of $\mathrm{SiC}$ was also found to affect the attack by $\mathrm{Pd}$ because the activation energy for this reaction would decrease

N. Jacobson—contributing editor

Manuscript No. 27838. Received April 12, 2010; approved June 24, 2010.

This work was financially supported by the EC FP7 Basic Research for Innovative Fuel Design for Gen IV systems (F-BRIDGE).

${ }^{\dagger}$ Author to whom correspondence should be addressed. e-mail: ping.xiao@manchester. ac.uk from $191 \mathrm{~kJ} / \mathrm{mol}$ when $\mathrm{SiC}$ was deposited at $1550^{\circ} \mathrm{C}$ down to $67 \mathrm{~kJ} / \mathrm{mol}$ when deposited at $\sim 1700^{\circ} \mathrm{C}^{4,10}$ The decrease in activation energy was related to the formation of large columnar grains as deposition temperature was increased. Overall, it has been suggested that large columnar heavily faulted grains (i.e., stacking faults or voids), produced at higher temperatures $\left(>1500^{\circ} \mathrm{C}\right)$ and high coating rates $(1 \mu \mathrm{m} / \mathrm{min})$, would have wider grain boundaries and provide a more direct diffusion path through grain boundaries, thus being deleterious to the performance of SiC. Several other investigations have been carried out to study the $\mathrm{Pd} / \mathrm{SiC}$ interaction because of their application in sensors and microelectronics; ${ }^{12}$ however, most of these studies have been carried out at temperatures below those relevant to nuclear fuel applications $\left(800^{\circ}-1600^{\circ} \mathrm{C}\right)$.

Currently, a new generation of $\mathrm{SiC}$ coatings is being produced aimed at improving their microstructure and mechanical properties. ${ }^{13-15}$ These coatings are characterized by being in some cases fully dense and having a refined grain size (grain sizes $<1 \mu \mathrm{m}$ ) and uniform microstructure throughout the entire coating. In contrast to the deposition conditions used in the past, i.e. deposition temperatures between $1500^{\circ}$ and $1600^{\circ} \mathrm{C}$ and coating rates of $0.2 \mu \mathrm{m} / \mathrm{min}$, these new types of coatings are being produced at temperatures as low as $1300^{\circ} \mathrm{C}$ and with coating rates as high as $\sim 1 \mu \mathrm{m} / \mathrm{min}$, conditions that based on previous studies could lead to a higher palladium attack. In this work, we aimed to methodically study the effect of $\mathrm{SiC}$ microstructure on the reactivity of $\mathrm{SiC}$ and $\mathrm{Pd}$. We have shown that the formation of $\mathrm{SiC}$ with optimized microstructure can reduce palladium attack by half when compared with standard coatings (produced at around $1500^{\circ} \mathrm{C}$ with only MTS as precursor), thus showing for the first time the possibility of controlling such an important deleterious effect on coated fuel particles. Similarly, the formation of long columnar grains and heavily faulted grains may not necessarily lead to an increase of attack by palladium, which is in contrast to what was claimed in previous studies. ${ }^{10}$

\section{Experimental Procedure}

The coated fuel particles studied were made by fluidized bed chemical vapor deposition. ${ }^{14} \mathrm{SiC}$ coatings were deposited on top of a high-density pyrolytic carbon layer, using alumina particles $500 \mu \mathrm{m}$ in diameter as the initial substrate. ${ }^{16,17}$ Table I shows the deposition conditions and main characteristics of the seven $\mathrm{SiC}$ coatings produced, including coating rate, stoichiometry, and grain size. These coatings were produced in order to study the effect of $\mathrm{SiC}$ with a range of microstructures (large columnar grains, equiaxed, and small columnar grains) and the effect of coating rate on the resistance of $\mathrm{SiC}$ to attack by Pd (Table I). Several SiC-coated particles and palladium powder (Sigma-Aldrich, Dorset, UK; particle size $<1 \mu \mathrm{m}, \geq 99.9 \%$ trace metal basis) were placed in an alumina crucible and heat treated in an argon atmosphere. No pressure was applied to the samples because early results showed that pressure would affect the $\mathrm{Pd} / \mathrm{SiC}$ reaction rate considerably producing scattered values. Samples of $\mathrm{SiC}$ and $\mathrm{Pd}$ were heat treated at $1000^{\circ}, 1100^{\circ}, 1200^{\circ}$, and $1300^{\circ} \mathrm{C}$ for $4 \mathrm{~h}$.

During heat treatment, all the Pd powders shrank forming cylindrical compacts with the particles inside. The particles were 
Table I. SiC Coating Characteristics and Pd/SiC Reaction Activation Energies

\begin{tabular}{llclrr}
\hline Samples & \multicolumn{1}{c}{ Deposition conditions $\left({ }^{\circ} \mathrm{C}\right.$, vol\% MTS $)$} & Coating rate $(\mu \mathrm{m} / \mathrm{min})$ & Stoichiometry & Grain size $(\mu \mathrm{m})$ & Activation energy $(\mathrm{kJ} / \mathrm{mol})$ \\
\hline $\mathrm{SiC} 1$ & $1300^{\circ} \mathrm{C}, 0.36 \mathrm{vol} \%$ MTS & 0.06 & $\mathrm{SiC}$ & $0.2-0.7$ & 69 \\
$\mathrm{SiC} 2$ & $1550^{\circ} \mathrm{C}, 0.17 \mathrm{vol} \%$ MTS & 0.08 & $\mathrm{SiC}$ & $1-2$ & 132 \\
$\mathrm{SiC} 3$ & $1300^{\circ} \mathrm{C}, 9.1 \mathrm{vol} \%$ MTS & 0.54 & $\mathrm{SiC}+\mathrm{Si}$ & $1-3$ & 140 \\
$\mathrm{SiC} 4$ & $1500^{\circ} \mathrm{C}, 9.1 \mathrm{vol} \%$ MTS & 0.69 & $\mathrm{SiC}$ & $2-6$ & 206 \\
$\mathrm{SiC} 5$ & $1300^{\circ} \mathrm{C}, 9.1 \mathrm{vol} \%$ MTS, $0.1 \mathrm{vol} \%$ propylene & 0.99 & $\mathrm{SiC}$ & $0.8-1$ & 236 \\
$\mathrm{SiC6}$ & $1300^{\circ} \mathrm{C}, 9.1 \mathrm{vol} \%$ MTS, 1 vol\% propylene & 1.01 & $\mathrm{SiC}+\mathrm{C}$ & $0.8-1.0$ & 256 \\
$\mathrm{SiC} 7$ & $1300^{\circ} \mathrm{C}, 9.1 \mathrm{vol} \%$ MTS, 0.5 vol\% propylene & 0.99 & $\mathrm{SiC}+\mathrm{C}$ & $0.4-0.8$ & 337 \\
\hline
\end{tabular}

MTS, methyltrichlorosilane.

placed inside the compacts in order to achieve uniform contact between $\mathrm{SiC}$ and $\mathrm{Pd}$. These compacts were embedded in copperloaded resin and ground/polished to the cross section of the particles. An optical microscope Olympus BH2 (Olympus UK Ltd., Essex, UK) with a $\times 100$ objective lens, coupled with ImageJ software, was used to measure the thickness of the coating before and after heat treatment in order to calculate the penetration of the $\mathrm{Pd}$ reaction. The microstructure and the $\mathrm{Pd} / \mathrm{SiC}$ reaction products were characterized by scanning electron microscopy (FEG-SEM JEOL 6300, Tokyo, Japan) combined with energy-dispersive X-ray spectroscopy and by X-ray diffraction (XRD) using a Philips PW1830 instrument equipped with $\mathrm{CuK \alpha _{1 }}$ radiation (Philips, Eindhoven, the Netherlands). Stoichiometry was characterized by Raman spectroscopy using a Renishaw 1000 Raman system (Renishaw plc., Gloucestershire, $\mathrm{UK}$ ) with an $\mathrm{He} / \mathrm{Ne}$ 633-nm-wavelength laser. Raman analysis was performed by single spot measurements of around $2 \mu \mathrm{m}$ using a $\times 50$ objective lens. Transmission electron microscopy samples of as-deposited $\mathrm{SiC}$ coatings were prepared by focused ion beam milling (dual beam FIB/SEM-FEI Nova Nanolab 600, FEI company, Hillsboro, OR) and observed with a TEM-FEI Tecnai G2 F30 (FEI company).

\section{Results}

Figure 1 shows the cross section of the $\mathrm{SiC} / \mathrm{Pd}$ reaction region in two samples ( $\mathrm{SiC}$ with excess $\mathrm{Si}$ and $\mathrm{SiC}$ with excess $\mathrm{C}$ ) thermally treated at $1200^{\circ} \mathrm{C}$. All of the samples heat treated at $1100^{\circ}$ and $1000^{\circ} \mathrm{C}$ showed a similar layered structure in the $\mathrm{SiC} / \mathrm{Pd}$ reaction region as that treated at $1200^{\circ} \mathrm{C}$. Table II shows the EDX point analysis results of the layer structures (shown in Fig. 1(b)) in the SiC7 ( $\mathrm{SiC}$ with C) sample after heat treatment at $1200^{\circ} \mathrm{C}$. The analyses suggest that all the layers were made up of a mixture of $\mathrm{Pd}_{x} \mathrm{Si}+\mathrm{C}$ with different $\mathrm{Pd}$ and $\mathrm{C}$ concentrations. The black layers (Fig. 1(b), point 2) had a much higher concentration of carbon up to 50 at. \% C, whereas the bright sections (points 3 and 5, Fig. 1(b)) had a higher concentration of Pd also up to 50 at. $\% \mathrm{Pd}$. The palladium concentration clearly increased from the interface with $\mathrm{SiC}$ (point 1) to the layer close to the palladium metal (point 6), from 19 to 55 at.\% Pd. There were clear differences in the thickness of the reaction zone (layered structure) between different samples. While the $\mathrm{SiC}$ with excess $\mathrm{Si}$ (SiC3 in Table I) had a reaction zone of around $16 \mu \mathrm{m}$, the reaction zone in the $\mathrm{SiC}$ with excess $\mathrm{C}$ ( $\mathrm{SiC} 7$ in Table I) was only around $9 \mu \mathrm{m}$ in thickness (the thinnest reaction zone among all samples). Figure 2 shows high-magnification SEM images with palladium preferentially located at the grain boundaries immediately after the $\mathrm{SiC} / \mathrm{Pd}_{x} \mathrm{Si}$ interface (Fig. 2(a), pointed by the arrows) and $5 \mu \mathrm{m}$ inside $\mathrm{SiC}$ (Fig. 2(b)) for the $\mathrm{SiC}$ coating with excess $\mathrm{Si}(\mathrm{SiC} 3)$. It seems that palladium was not uniformly distributed in all the grain boundaries observed, suggesting preferred diffusion through a certain type of grain boundary. This advanced diffusion front and $\mathrm{Pd}$ at the grain boundaries was not observed in the optimized sample $\mathrm{SiC}$ with carbon $(\mathrm{SiC} 7$ in Table I), a dense SiC coating with uniform microstructure of around $0.4-0.7 \mu \mathrm{m}$ grain size. Figure 3 showed that the $\mathrm{SiC} /$ $\mathrm{Pd}_{x} \mathrm{Si}$ interfaces from two samples after reaction between $\mathrm{Pd}$ and
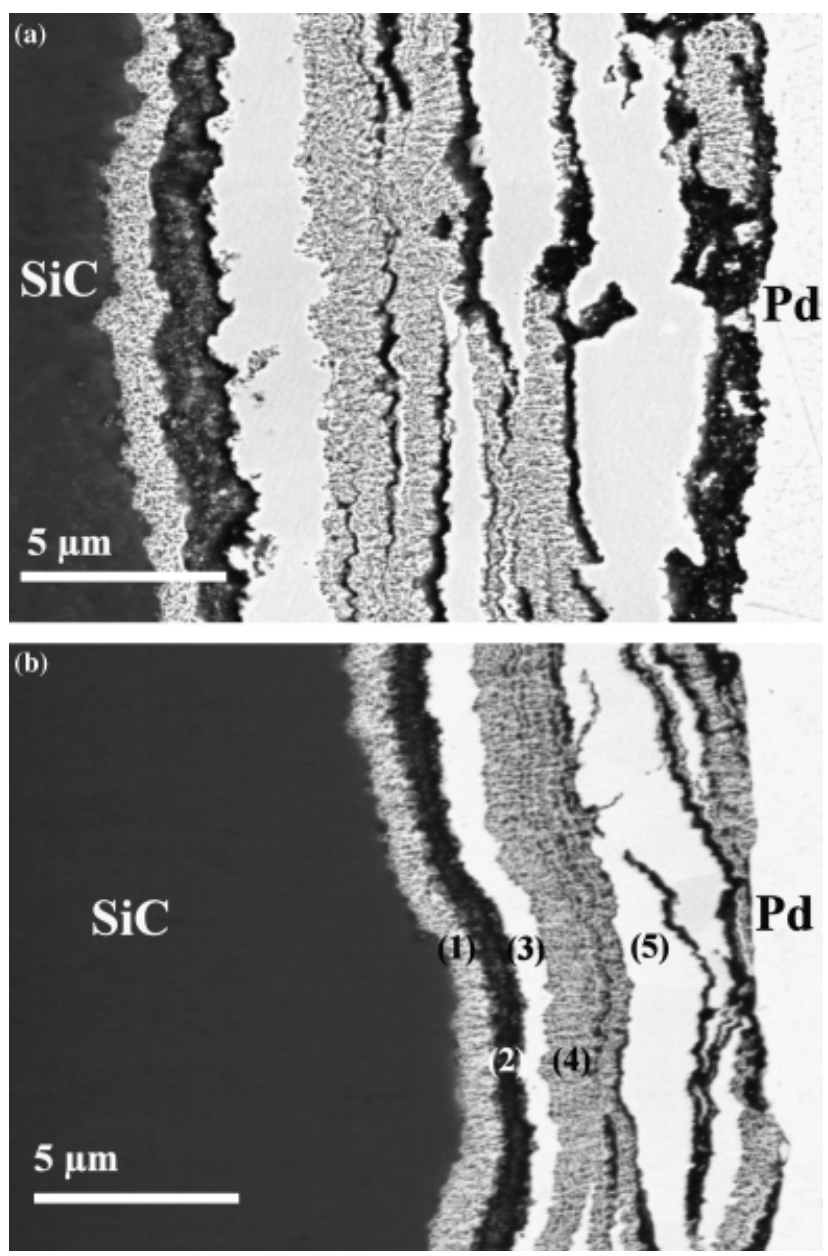

Fig. 1. Silicon carbide $(\mathrm{SiC}) / \mathrm{Pd}$ periodic layer interface obtained after heat treatment of (a) $\mathrm{SiC}$ with excess $\mathrm{Si}$ ( $\mathrm{SiC} 3$ in Table I) and (b) $\mathrm{SiC}$ with excess $\mathrm{C}\left(\mathrm{SiC} 7\right.$ in Table I) at $1200^{\circ} \mathrm{C}$ for $4 \mathrm{~h}$. Numbers $1-5$ correspond to EDX point analysis taken from sample $\mathrm{SiC} 7$ and shown in Table II.

$\mathrm{SiC} 3$ or $\mathrm{SiC} 7$ (see Table I for sample details), where the sample $\mathrm{SiC} 3$ ( $\mathrm{SiC}$ with carbon) had pits of around $300 \mathrm{~nm}$ apparently being formed by the dissociation of $\mathrm{SiC}$ (feature (i) in Fig. 3(a)). The formation of these pits appears to be the origin of the porous structure of the area marked as $\mathrm{Pd}_{x} \mathrm{Si} / \mathrm{C}$. It is also

Table II. EDX Element Analysis of the SiC/Pd Interface of Sample SiC7 in Fig. 1(b)

\begin{tabular}{lccccc}
\hline Elements & $\begin{array}{c}\text { Point 1 } \\
\text { (at.\%) }\end{array}$ & $\begin{array}{c}\text { Point 2 } \\
\text { (at.\%) }\end{array}$ & $\begin{array}{c}\text { Point 3 } \\
\text { (at.\%) }\end{array}$ & $\begin{array}{c}\text { Point 4 } \\
\text { (at.\%) }\end{array}$ & $\begin{array}{c}\text { Point 5 } \\
\text { (at.\%) }\end{array}$ \\
\hline Silicon & 49.0 & 21.3 & 19.5 & 14.5 & 24.5 \\
Carbon & 31.2 & 50.3 & 37.2 & 54.8 & 20.3 \\
Palladium & 19.8 & 28.4 & 43.3 & 30.7 & 55.2 \\
\hline
\end{tabular}



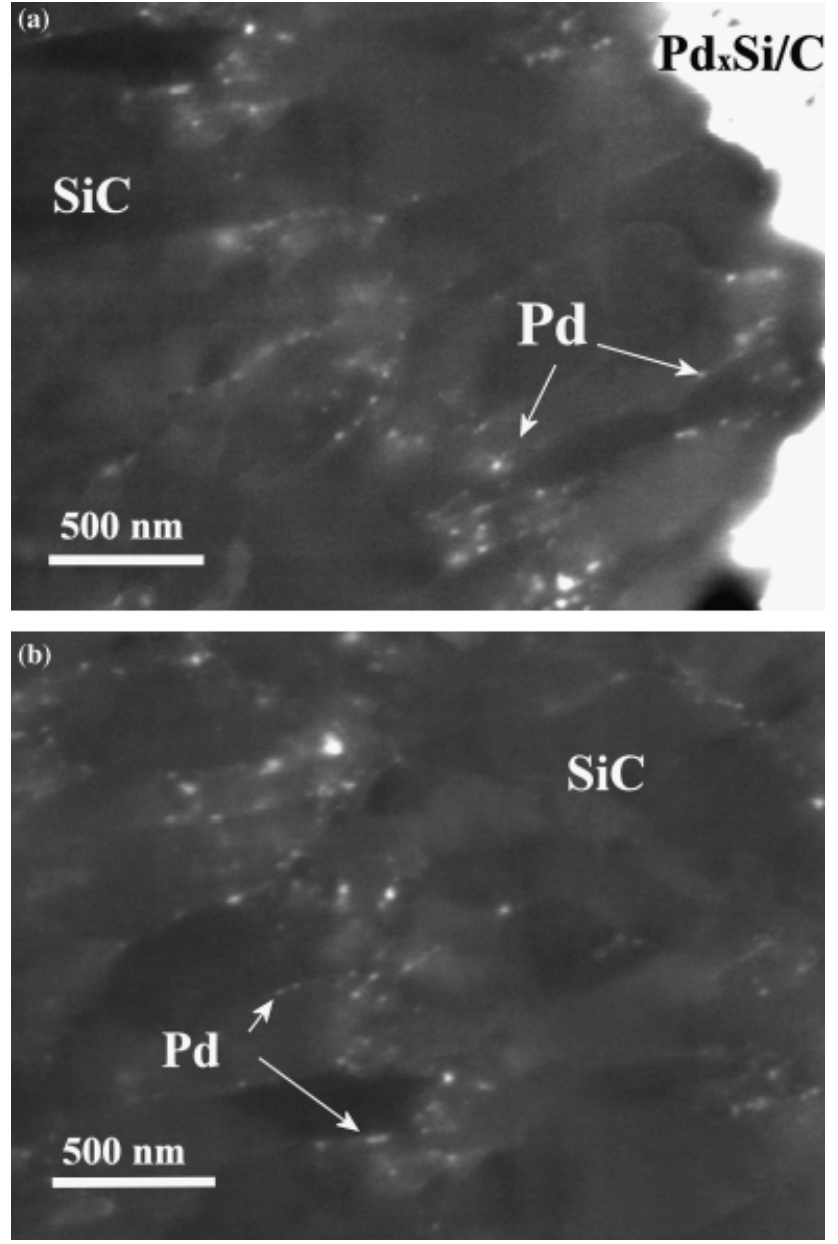

Fig. 2. Palladium penetration beyond the $\mathrm{Pd}_{x} \mathrm{Si} / \mathrm{SiC}$ interface in sample $\mathrm{SiC} 3$ (Table I). (a) $\mathrm{SiC} / \mathrm{Pd}_{\mathrm{x}} \mathrm{Si}$ interface and (b) $5 \mu \mathrm{m}$ inside $\mathrm{SiC}$.

possible that these regions of porosity contain a higher concentration of carbon. Although in the sample SiC7 (Fig. 3(b)) there are also the formation of pits, they appear to be smaller with a less rough interface between the $\mathrm{SiC}$ and the porous structure of $\mathrm{Pd}_{x} \mathrm{Si} / \mathrm{C}$ than that in the sample $\mathrm{SiC} 3$.

In contrast, at $1300^{\circ} \mathrm{C}$ all the $\mathrm{SiC}$ coatings tested fully reacted with $\mathrm{Pd}$ to produce a layered structure of palladium silicides $\left(\mathrm{Pd}_{x} \mathrm{Si}\right)$ and carbon (Fig. 4). XRD analysis (not shown) of some of these samples confirmed the formation of $\mathrm{Pd}_{2} \mathrm{Si}$ and $\mathrm{Pd}_{3} \mathrm{Si}$ as products of the $\mathrm{Pd} / \mathrm{SiC}$ reaction at $1300^{\circ} \mathrm{C}$. The variation in $\mathrm{Pd} /$ $\mathrm{C}$ concentration is evident in the sample heat treated at $1300^{\circ} \mathrm{C}$ (Fig. 4(b)). For this case, the domains where carbon or palladium dominates are more clearly defined, reaching concentrations of around 90 at. \% for $\mathrm{C}$ and 80 at. \% for Pd.

Although the depth of the reaction zone showed clear evidence that some samples suffered less attack by palladium than others, the reaction zone itself is not used as a measure of the reaction rate because some of that thickness belonged to regions that were originally $\mathrm{Pd}$. Here, we are only interested in the Pd penetration into $\mathrm{SiC}$. Therefore, the penetration depth into $\mathrm{SiC}$ by $\mathrm{Pd}$ was an indication of reaction intensity, which was obtained by measuring the reduction in the SiC-coating thickness after the reaction. Figure 5 shows the effect of the temperature on the Pd reaction rate $(\mu \mathrm{m} / \mathrm{h})$. For most of the samples, the reaction rate increased considerably at each $100^{\circ} \mathrm{C}$ increment. For example, the reaction rate of one $\mathrm{SiC}$ sample ( $\mathrm{SiC} 4$ in Table I) changed from 0.09 to $0.8 \mu \mathrm{m} / \mathrm{h}$ then to $1.1 \mu \mathrm{m} / \mathrm{h}$ as temperature increased from $1000^{\circ}$ to $1100^{\circ} \mathrm{C}$ then to $1200^{\circ} \mathrm{C}$, respectively. At $1300^{\circ} \mathrm{C}, \mathrm{SiC}$ coatings with an original thickness of around $60 \mu \mathrm{m}$ (SiC7, Fig. 2) were totally transformed into a $\mathrm{Pd}_{x} \mathrm{Si}+\mathrm{C}$-layered structure, suggesting reaction rates as high as $15 \mu \mathrm{m} / \mathrm{h}$ at this temperature. Among all the samples analyzed in Fig. 5, SiC7 showed a considerable reduction in palladium attack at both $1100^{\circ}$ and $1200^{\circ} \mathrm{C}$ in comparison with other samples.

The results in Fig. 5 were used to calculate the activation energy for this reaction using an Arrhenius relationship with temperature. ${ }^{9,10}$ The values obtained, shown in Table I, changed from 69 to $206 \mathrm{~kJ} / \mathrm{mol}$ for samples deposited from only $\mathrm{H}_{2}$ and MTS at $1300^{\circ}-1550^{\circ} \mathrm{C}$, which is used to produce standard $\mathrm{SiC}$ coatings. These values are very similar to those reported by Pearson et al. ${ }^{10}$ from 67 to $191 \mathrm{~kJ} / \mathrm{mol}$. Conversely, those coatings formed with the addition of propylene ( $\mathrm{SiC} 5-\mathrm{SiC} 7)$ showed higher activation energies from 236 up to $337 \mathrm{~kJ} / \mathrm{mol}$ (almost double the other standard samples).

The texture of the $\mathrm{SiC}$ coatings was investigated by XRD analysis because the thick SiC coating $(60 \mu \mathrm{m})$ and the presence of an alumina kernel ( $500 \mu \mathrm{m}$ in diameter) preclude the X-rays from fully penetrating the particle. The texture coefficient (TC), used here more as a qualitative measure, was obtained according to ${ }^{18}$ :

$$
\mathrm{TC}(h k l)=\frac{I_{(h k l)} / I_{0(h k l)}}{\frac{1}{N} \sum\left(I_{(h k l)} / I_{0(h k l)}\right)}
$$

where $I_{(h k l)}, I_{0(h k l)}$, and $N$ are the measured intensities from each diffracting plane of the samples, the intensities of the standard material (powder diffraction file 00-029-1129), and the number of reflections, respectively. Figure 6 illustrates the changes in TC for all the samples analyzed. There seems to be a clear difference between the texture obtained for samples with low ( $\mathrm{SiCl}$ and $\mathrm{SiC} 2$ ) and medium/high activation energy (SiC3-SiC7). Whereas samples giving a bad performance had dominant (220) and (222) texture components, samples with a medium/high activation energy had a clear increase in the (111) texture component, SiC5 having the highest (111) texture component among all the samples. Overall, the pattern of the (111) texture component seems to increase with activation energy (Table I). Discussion on this will be given later.

Figure 7 and Table I show that the samples tested had a considerable variation in microstructure, going from samples with grain sizes as small as $200 \mathrm{~nm}$ (Fig. 7(b)) to several micrometers (Fig. 7(c)). Although most of the samples had a clear columnar structure, sample SiC2 had almost equiaxed grains (Fig. 7(a)) with grain sizes of around 1-2 $\mu \mathrm{m}$. Figure 8 shows TEM images of samples $\mathrm{SiC} 3, \mathrm{SiC} 4$, and $\mathrm{SiC7}$ (with low, medium, and high activation energies, respectively), revealing the formation
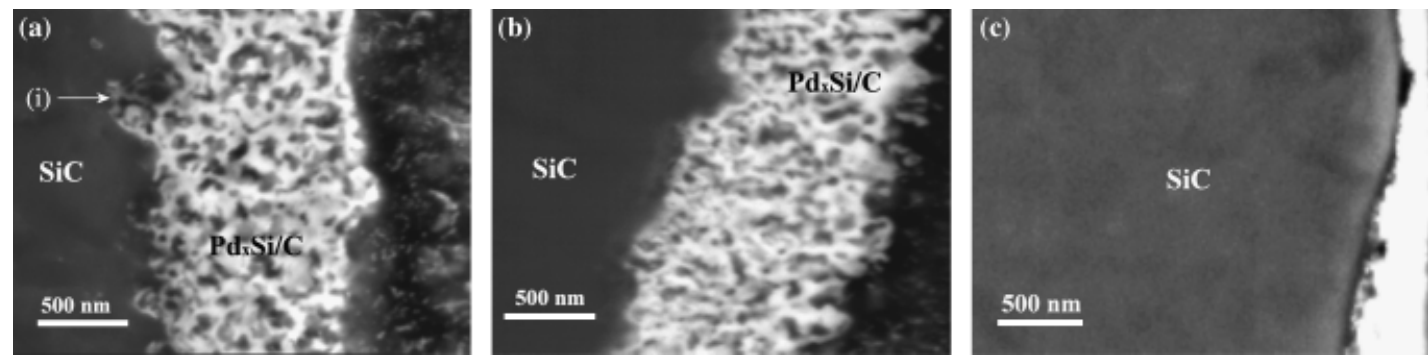

Fig. 3. Differences in the $\mathrm{SiC} / \mathrm{Pd}_{x} \mathrm{Si}$ interface of Pd reacted with (a) $\mathrm{SiC}$ with excess $\mathrm{Si}$ ( $\mathrm{SiC} 3$ in Table I) ((i), pits formed due to the reaction between Pd and $\mathrm{SiC}$ ) and (b) $\mathrm{SiC}$ with $\mathrm{C}(\mathrm{SiC} 7$ in Table $\mathrm{I})$. (c) $\mathrm{SiC} 7$ surface before $\mathrm{Pd} / \mathrm{SiC}$ reaction. 

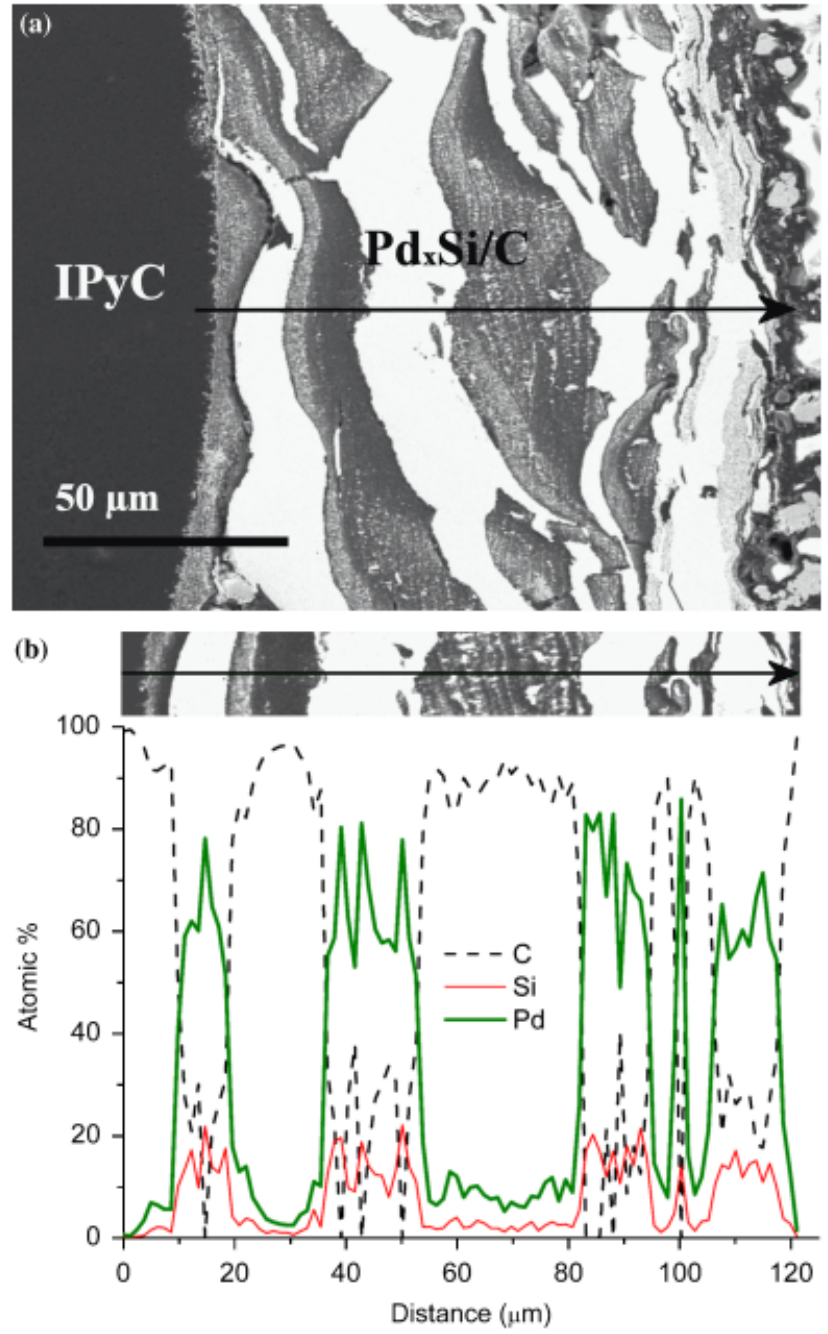

Fig. 4. (a) $\mathrm{SiC} 7$ coating heat treated at $1300^{\circ} \mathrm{C}$ for $4 \mathrm{~h}$. No $\mathrm{SiC}$ coating was left, only the layered structure made of palladium silicides $\left(\mathrm{Pd}_{x} \mathrm{Si}\right)$ and carbon remained. The arrow shows the EDX line analysis shown in (b).

of columnar grains with a high concentration of stacking faults. Interestingly, the grain-boundary morphology, especially grainboundary roughness, seems to increase for the samples with higher activation energy and more resistance to palladium attack. Whereas sample $\mathrm{SiC} 3$ generally showed flat well-defined grain boundaries between columnar grains (Fig. 8(a)), sample SiC4 showed a rougher grain-boundary morphology (Fig. 8(b)),

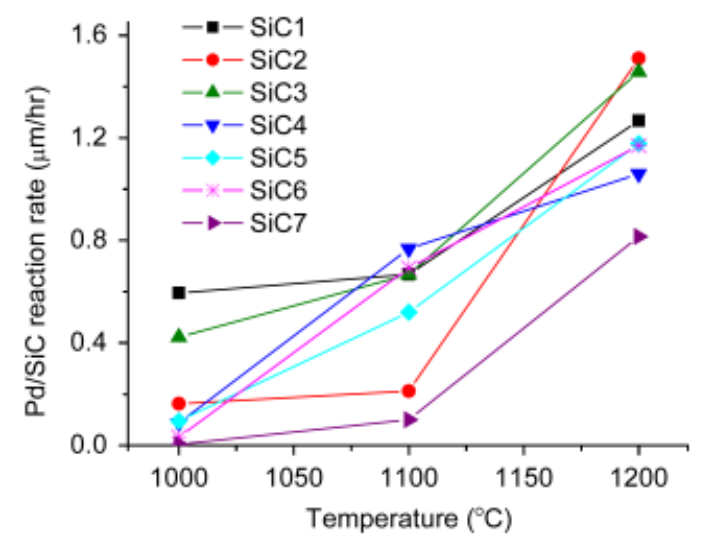

Fig. 5. Reaction rate between $\mathrm{Pd}$ and $\mathrm{SiC}$. Above $1300^{\circ} \mathrm{C}$, there was total penetration of $\mathrm{SiC}$ up to $100 \mu \mathrm{m}$ thick. Error bars (not included) are approximately \pm 0.2 for samples heat treated up to $1100^{\circ} \mathrm{C}$ and $\pm 0.4 \mu \mathrm{m} / \mathrm{h}$ at $1200^{\circ} \mathrm{C}$ (except SiC2 with an error bar of $\pm 0.7 \mu \mathrm{m} / \mathrm{h}$ ).

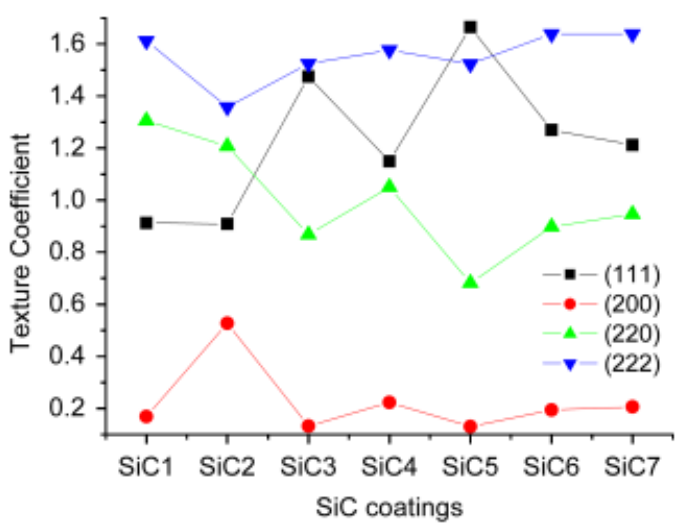

Fig. 6. Differences in texture between samples measured by X-ray diffraction.

while $\mathrm{SiC} 7$ had a columnar structure with very rough grain boundaries, even having grains with odd shapes (Fig. 8(c)).

\section{Discussion}

The formation of periodic-layered structures is generally observed in the reaction between bulk $\mathrm{SiC}$ and $\mathrm{Pd}$ as well as other metal/ceramic systems. ${ }^{19,20}$ Different theories have been proposed to explain the formation of such structures..$^{20-23} \mathrm{KaO}$ and Chang $^{21}$ proposed that this structure originates due to a periodic thermodynamic instability occurring at the interface between the substrate and the product. This instability occurs due to the large difference in mobility between palladium (the largest mobility) and silicon and carbon. ${ }^{6}$ Gutman et $a l^{22}$ and Klinger et al. ${ }^{24}$ suggest that these periodic layers originate due to changes in supersaturation of the elements required to nucleate each phase. Overall, palladium is considered the dominant diffusion species and carbon is considered almost immobile. At the initial stage of the reaction between $\mathrm{Pd}$ and $\mathrm{SiC}$ two layers are formed, one $\mathrm{Pd}_{x} \mathrm{Si}$ rich ( $\beta$ phase in Fig. $\left.9(\mathrm{~b})\right)$ and a second layer carbon rich ( $\alpha$ phase in Fig. 9(b)) due to the diffusion of silicon at the $\alpha / \beta$ interface. As the reaction continues, it is believed that $\mathrm{Si}$ will accumulate at the $\mathrm{SiC} / \alpha$ interface due to its increasing difficulty in diffusing through the $\alpha$ phase (Gutman et al. theory), or the activity of Pd will increase (Kao and Chang theory), thus promoting the formation of a secondary $\mathrm{Pd}_{x} \mathrm{Si}$ rich ( $\beta$ phase in Fig. 9(c)). Subsequently, the diffusion of Si to the newly formed $\mathrm{SiC} / \beta$ will cause a depletion of $\mathrm{Si}$ atoms (Kao and Chang theory), triggering the formation of a carbon-rich phase ( $\alpha$ phase in Fig. 9(d)). It has also been considered that the new $\alpha$ phase could originate due to the lack of a stable $\mathrm{SiC} / \alpha$ interface. $^{23,25}$ This will continue to repeat itself leading to the formation of the periodic-layered structure shown in Figs. 1 and 4.

Although the formation of periodic-layered structures (as shown in Figs. 1 and 4) are not common for reactions in actual fuel pellets, our experiments can provide an insight into the importance of the $\mathrm{SiC}$ microstructure in reducing the reaction rate between $\mathrm{Pd}$ and $\mathrm{SiC}$. Palladium in coated fuel, having a lower activity than that in our experiments, considered to be almost 1, would explain for the lack of a periodic layer formation in actual fuel particles. ${ }^{7,21}$ Similarly, whereas in our experiments $\mathrm{Pd}$ can diffuse quickly and constantly due to high concentration of $\mathrm{Pd}$ in direct contact or in short distance from $\mathrm{SiC}, \mathrm{Pd}$ in active fuel has to be first formed in the uranium kernel and then diffuse through the kernel and two layers of pyrolytic carbon to later interact with $\mathrm{SiC}^{3}$ These differences would explain the considerably higher reaction rates $(1.2 \mu \mathrm{m} / \mathrm{min})$ compared with those measured in actual fuel particles of around $1 \times 10^{-3} \mu \mathrm{m} / \mathrm{h}$, both at $1200^{\circ} \mathrm{C}^{2}$

The identification of $\mathrm{Pd}_{2} \mathrm{Si}$ and $\mathrm{Pd}_{3} \mathrm{Si}$ agrees with previous reports of $\mathrm{Pd} / \mathrm{SiC}$ reaction couples at temperatures $1000^{\circ}$ $1300^{\circ} \mathrm{C}$ and phase diagrams of $\mathrm{Pd}-\mathrm{Si}-\mathrm{C} .^{5,26}$ The $\mathrm{Pd}-\mathrm{Si}$ phase 

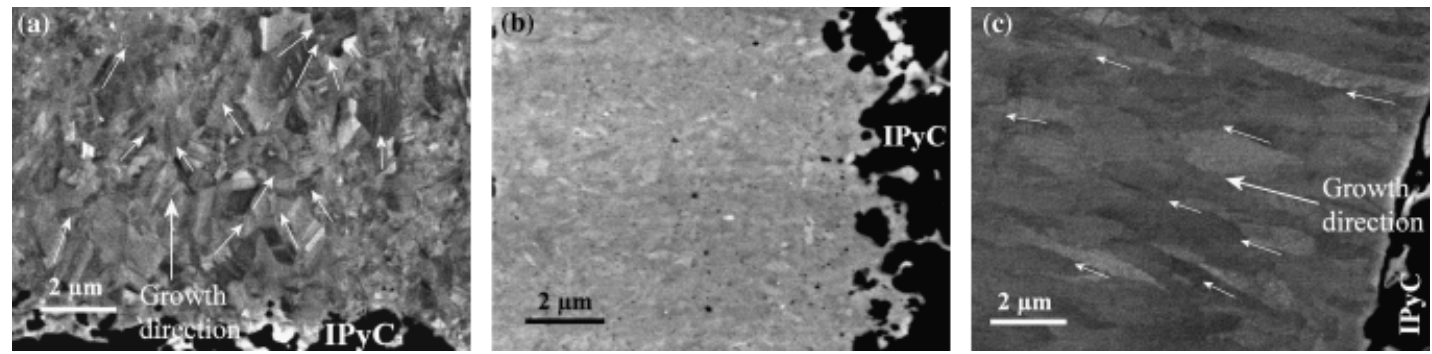

Fig. 7. Scanning electron microscopic images showing the differences in microstructure between samples (a) $\mathrm{SiC} 2$; (b) $\mathrm{SiCl}$; and (c) $\mathrm{SiC} 4$.

diagrams also predict the formation of an eutectic phase that will melt at around $800^{\circ} \mathrm{C} .^{9,26}$ It has been suggested that this eutectic phase is formed by the reaction between $\mathrm{Pd}_{3} \mathrm{Si}$ and $\mathrm{Pd} .{ }^{9}$ The $\mathrm{Pd}-\mathrm{Si}-\mathrm{C}$ phase diagrams also suggest that as temperature and $\mathrm{Pd}$ content increases, the formation of liquid phases is favored therefore enhancing the material transport and increasing $\mathrm{Pd} / \mathrm{SiC}$ reaction rates as it is seen in Fig. 4 where all the $\mathrm{SiC}$ had already reacted.

It is important to mention that other factors such as radiation damage in active fuel could increase $\mathrm{Pd}$ diffusion and $\mathrm{Pd} / \mathrm{SiC}$ reaction rate by the formation of amorphous phases and defects (i.e., vacancies, voids, dislocation networks, etc.). ${ }^{27-30}$ Similarly, because the $\mathrm{Pd} / \mathrm{SiC}$ interaction is strongly affected by temperature, the existence of temperature gradients in the fuel will have a strong effect on the $\mathrm{Pd} / \mathrm{SiC}$ reaction rate. ${ }^{3}$ The results shown here nevertheless suggest that microstructure can play an important role in reducing attack by palladium of $\mathrm{SiC}$. Despite this, several contradictions have been identified between what was reported in the past and the results obtained here. For example, Tiegs ${ }^{2}$ observed that the penetration by palladium would increase with the coating rate. Pearson et al. ${ }^{10}$ supported this idea by suggesting that this was due to the formation of more disordered and wider grain boundaries as a result of the formation of heavily faulted grains. Probably, the opposite could be the said based on the results found in Table I, in which the samples with the highest coating rates (up to $1 \mu \mathrm{m} / \mathrm{min}$ ) were those the most resistant to attack by Pd as shown by their activation energies (SiC5-SiC7). Despite these results, we cannot claim that high coating rates would improve palladium resistance because a value of coating rate is meaningless in terms of deposition conditions and the characteristics/performance that $\mathrm{SiC}$ could have because coating rate depends on many other variables such as deposition temperature, precursor concentration, surface area/volume ratio, and residence time, all of their having a strong effect on the microstructure of $\mathrm{SiC}$. Therefore, coating rate cannot be truly related to $\mathrm{Pd} / \mathrm{SiC}$ reactions rates. It is the changes in microstructure that affect the reactivity between Pd and SiC. Furthermore, the idea that heavily faulted grains would increase attack by Pd was also found to be not totally true because as can be seen in Fig. 8, samples with a good performance ( $\mathrm{SiC} 3$ and $\mathrm{SiC} 4)$ also had a high density of stacking faults.

Also in contrast to what was found in this study is the result from Pearson et al., ${ }^{10}$ who showed that high deposition temperatures (above $1600^{\circ} \mathrm{C}$ ) would increase the attack by $\mathrm{Pd}$ (reduced activation energy down to $67 \mathrm{~kJ} / \mathrm{mol}$ ) due to the formation of large columnar grains with more direct diffusion paths. A similar value of the activation energy was obtained for the sample $\mathrm{SiCl}$ (69 kJ/mol) (Fig. 7(b) and Table I), despite being stoichiometric and having a grain size of $0.2-0.7 \mu \mathrm{m}$, much smaller grain size than that possibly obtained by Pearson et al. ${ }^{10}$ (columnar structure of several micrometers in length). It appears that grain size cannot provide a direct correlation with the performance of $\mathrm{SiC}$, because large columnar grains do not imply a bad performance. For example, coating SiC4 (Fig. 7(a) and Table I) had the largest grain size with a similar activation energy to the best sample reported by Pearson et al. ${ }^{10}$ Likewise, coatings with small grain sizes (above $200 \mathrm{~nm}$ ) does not mean samples more resistant to Pd attack, because coating SiC1 with the smallest grain size also had the lowest activation energy (Fig. 7(b) and Table I). It should be noted that as deposition temperature increases from the "optimized" condition (around $1500^{\circ}-1600^{\circ} \mathrm{C}$ for the mixture $\mathrm{MTS} / \mathrm{H}_{2}$ only), carbon is codeposited along with $\mathrm{SiC}$ and more importantly more porosity is produced. ${ }^{31}$ Therefore, it is unlikely that the reason for the low value of activation energy was grain size itself as suggested before, but it may be associated with the increase in porosity in the SiC coatings (Fig. 7(b)). A larger amount of porosity will no doubt produce much easier diffusion paths and as has seen in other systems could concentrate the corrosion of $\mathrm{Pd}$ in $\mathrm{SiC}$ around pores. ${ }^{32,33}$ Surely, the presence of porosity will increase the corrosion rate of palladium, but it cannot be considered the controlling factor in the interaction $\mathrm{Pd} / \mathrm{SiC}$. For example, Fig. 10 shows that coating SiC5, despite having a very good performance (activation energy of $236 \mathrm{~kJ} / \mathrm{mol}$ ), had a considerable amount of really small pores (generally below $100 \mathrm{~nm}$ ) distributed parallel to the deposition plane. This suggests that other microstructural features must be playing more important roles.

Figure 6 suggests that the (111) texture component plays a role in improving the performance of $\mathrm{SiC}$ because the trend of
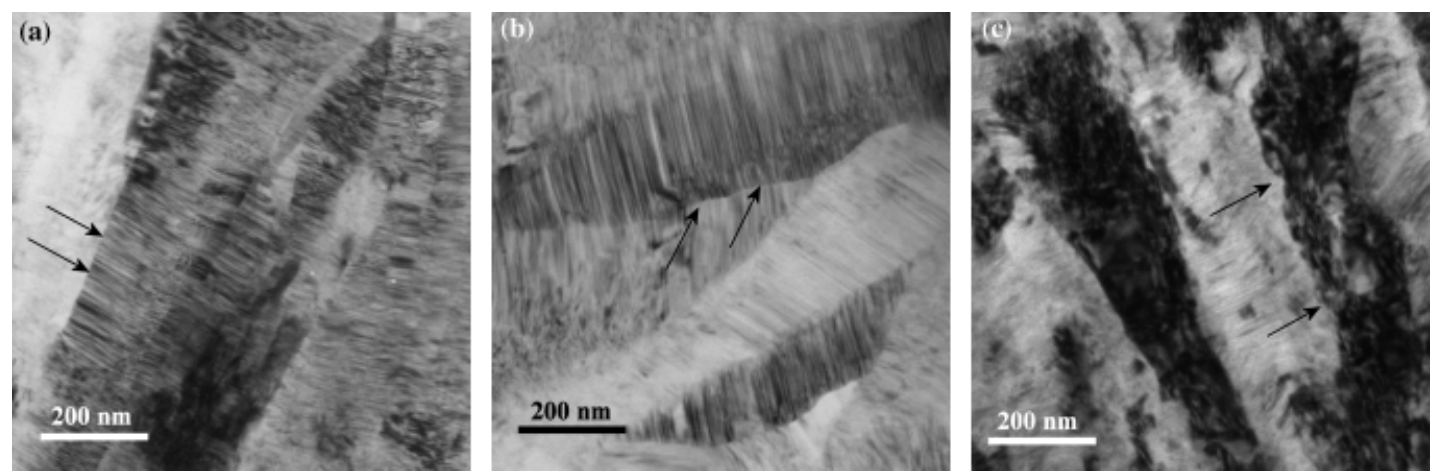

Fig. 8. TEM images of samples (a) $\mathrm{SiC} 3$, (b) $\mathrm{SiC} 4$, and (c) $\mathrm{SiC} 7$, showing changes in the grain-boundary morphology. Arrows point to differences in grain-boundary roughness. 
(a)

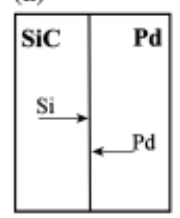

(b)

$\alpha=$ Carbon rich

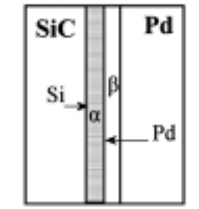

(c)

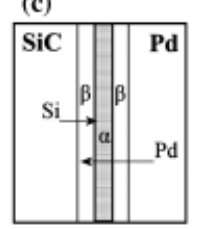

$\beta=P d x$ Si rich (d)

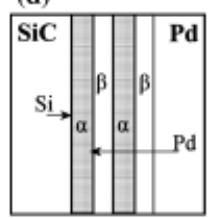

Fig. 9. Schematic showing the formation of a periodic layer structure. Modified from He et al. ${ }^{23}$

the (111) texture component in general increases from sample $\mathrm{SiCl}$ to $\mathrm{SiC7}$, the same trend as the activation energy (Table I). These results support the idea that texture, specially the (111) component, can lead to improvements in corrosion resistance of SiC. ${ }^{18,34}$ However, sample SiC7 (with an activation energy of $337 \mathrm{~kJ} / \mathrm{mol}$ ) is not the coating with the highest (111) texture component, but rather it is sample $\mathrm{SiC} 5$. It is possible that $\mathrm{SiC} 5$ did not perform better due to the clear presence of porosity (Fig. 10), which as mentioned before will increase the reaction rate between $\mathrm{Pd}$ and $\mathrm{SiC}$, although such porosity may play less significant role than the texture. Therefore, SiC5 possibly did not perform as badly as would be expected with the high amount of porosity due to a higher (111) texture component. Sample SiC3, which had the second highest (111) texture component, was not among the best samples, most likely due to the presence of excess Si (only detectable by Raman spectroscopy on the edge of the $\mathrm{SiC}$ where the reaction occurred). The $\mathrm{Si}$ will be preferentially attacked ${ }^{35}$ and react readily with $\mathrm{Pd}$ to form palladium silicides. The surface energy in $\mathrm{SiC}$ changes with crystal orientation. The (111) plane is the most densely populated plane with the lowest surface energy and the lowest surface atomic density (only the $\mathrm{C}$ or $\mathrm{Si}$ face at the uppermost surface). ${ }^{36,37}$ The low surface energy makes this plane thermodynamically stable and reduces the number of available free surface bonds capable of reacting with $\mathrm{Pd}$, thus increasing its resistance to $\mathrm{Pd}$ attack. ${ }^{36,38}$ Generally, standard $\mathrm{SiC}$ coatings produced at around $1400^{\circ}-1500^{\circ} \mathrm{C}$ have a weak (111) texture component, similar to that found for sample SiC2 (Fig. 6). ${ }^{39,40}$ Kajikawa et al. ${ }^{37}$ has suggested that the (111) texture component could be increased by depositing $\mathrm{SiC}$ in a reaction-limited regime (the growth rate limited by the surface reaction). This could be achieved in conditions of a low deposition temperature and high MTS concentration.

Grain boundaries can be considered as discontinuities in the regular crystal structure. Depending on the misorientation between adjacent grains, the grain-boundary energy increases. Therefore, atoms at the grain boundary are generally favored as

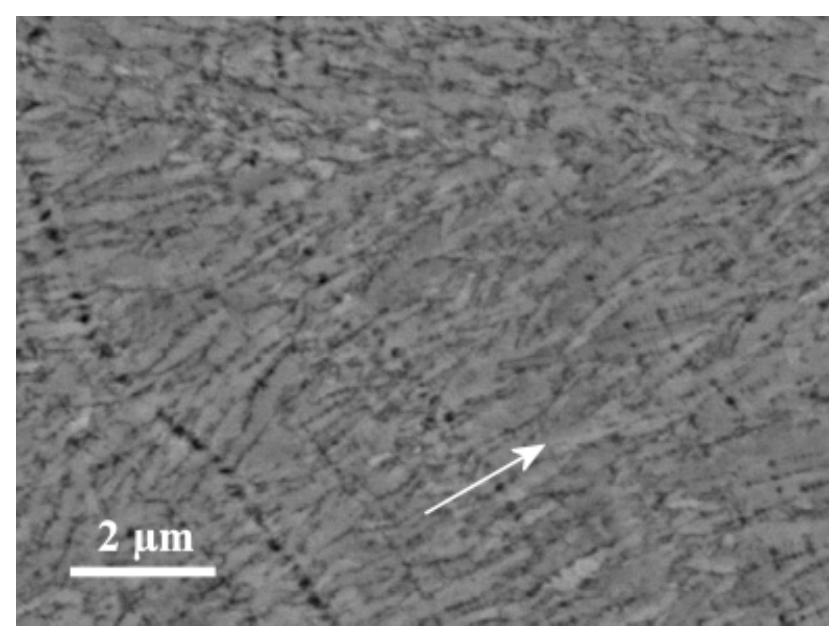

Fig. 10. SiC5 etched showing the presence of porosity. Arrow shows the direction of deposition. reaction sites for chemical attack due to their higher energy. ${ }^{36}$ This is true for the $\mathrm{Pd}$ corrosion of $\mathrm{SiC}$ in which the reaction is controlled by grain-boundary diffusion (Fig. 2). Therefore, the characteristics of the grain boundary are bound to be a fundamental importance in the performance of a material. Generally, the control of the properties of a grain boundary, mainly low- $\Sigma$ coincidence site lattice boundaries $(5 \leq \Sigma \leq 29$, low-energy grain boundaries), has lead to improvements in stress corrosion cracking and fracture toughness of other materials. ${ }^{41}$ Low-energy grain boundaries have already shown to be also more resistant to corrosive attack. ${ }^{34}$ Interestingly, it has been observed that standard coatings are composed of mainly large-angle boundaries (with a higher grain-boundary energy) due to a random grain growth that increases the misorientation between grains. ${ }^{40}$ This is clear in sample SiC2 (Fig. 7(a)) in which grains are not oriented perpendicular to the eposition plane (arrows in Fig. 7(a) show that the orientation of the grains is not parallel to growth direction). This type of misorientation was not observed in samples $\mathrm{SiC} 4-\mathrm{SiC7}$, in which most of the grains were oriented parallel to the growth direction (arrows in Fig. 7(c) are mostly parallel to growth direction), which also probably led to a higher (111) texture component. Therefore, it is possible that the improved corrosion resistance was also due to an increase in the percentage of low-angle grain boundaries. Additionally, it has been shown that some elements when segregated to the grain boundaries can reduce grain-boundary energy. Consequently, it could be possible that the excess carbon found in samples SiC5$\mathrm{SiC} 7$ could also reduce the grain-boundary energy. Furthermore, it has been considered that planar grain boundaries, such as those in samples with higher palladium attack (sample $\mathrm{SiC} 3$ in Fig. 8(a)), can provide more direct diffusion paths for palladium. ${ }^{10}$ As a result, it is expected that rougher grain boundaries observed in samples with lower palladium attack (coatings SiC4 and SiC7), such as those shown in Fig. 8(c) (pointed by arrows), would slow down palladium diffusion. However, further study is required to reach solid conclusions on the effect of grain boundaries.

\section{Conclusions}

It has been shown that by controlling the texture and the characteristics of the grain boundaries in $\mathrm{SiC}$, it is possible to reduce attack by $\mathrm{Pd}$ at temperatures below $1200^{\circ} \mathrm{C}$. The optimization of the deposition conditions in terms of $\mathrm{SiC}$ coatings with higher (111) texture component, rough and possibly lower angle grain boundaries has lead to a reduction of palladium attack by half when compared with a standard coating. This was achieved by depositing $\mathrm{SiC}$ at lower temperatures $\left(1300^{\circ} \mathrm{C}\right)$ using MTS and propylene as precursors. Meanwhile, porosity and excess Si have a clear deleterious effect on the resistance of SiC to attack by Pd, therefore it is necessary to produce fully dense and stoichiometric coatings. The grain size and the presence of stacking faults showed no important effect on the corrosion resistance of $\mathrm{SiC}$.

\section{References}

${ }^{1}$ D. A. Petti, J. Buongiorno, J. T. Maki, R. R. Hobbins, and G. K. Miller, "Key Differences in the Fabrication, Irradiation and High Temperature Accident Testing of US and German TRISO-Coated Particle Fuel, and their Implications on Fuel Performance," Nucl. Eng. Des., 222, 281-97 (2003).

${ }^{2}$ T. N. Tiegs, "Fission Product Pd-SiC Interaction in Irradiated Coated-Particle Fuels," Nucl. Technol., 57, 389-98 (1982).

${ }^{3}$ K. Minato, T. Ogawa, S. Kashimura, K. Fukuda, M. Shimizu, Y. Tayama, and I. Takahashi, "Fission Product Palladium-Silicon Carbide Interaction in HTGR Fuel Particles," J. Nucl. Mater., 172, 184-96 (1990).

${ }^{4}$ R. J. Lauf, T. B. Lindemer, and R. L. Pearson, "Out-of-Reactor Studies of Fission Product-Silicon Carbide Interactions in HTGR Fuel Particles," J. Nucl. Mater., 120, 6-30 (1984).

${ }^{5} \mathrm{H}$. Suzuki, T. Iseki, and T. Imanaka, "Reactions Between $\mathrm{SiC}$ and $\mathrm{Pd}$ or $\mathrm{CeO}_{2}$ at High Temperatures," J. Nucl. Sci. Technol., 14 [6] 438-42 (1977).

${ }^{6} \mathrm{~K}$. Bhanumurthy and R. Schmid-Fetzer, "Experimental Study of Ternary Pd-Si-C Phase Equilibria and Pd/SiC Interface Reactions," Z. Metallkd., 87 [4] 244-53 (1996).

${ }^{7}$ T. Ogawa and K. Ikawa, "Reactions of Pd with $\mathrm{SiC}$ and $\mathrm{ZrC}$," High Temp. Sci., 22, 179-93 (1986). 
${ }^{8}$ J. T. Maki, D. A. Petti, L. Knudson, and G. K. Miller, "The Challenge Associate with High Burnup, High Temperature and Accelerated Irradiation for TRISO-Coated Particle Fuel,” J. Nucl. Mater., 371, 270-80 (2007).

${ }^{9}$ V. Haase, G. Kirschtein, H. List, S. Ruprecht, R. Sangster, F. Schroder, W. Topper, and H. Vanecek, Gmelin Handbook of Inorganic Chemistry, Silicon, Vol. B3, 8th edition, Springer-Verlag, New York, 1986, p. 31.

${ }^{10}$ R. L. Pearson, R. J. Lauf, and T. B. Lindemer, The Interaction of Palladium, the Rare Earths, and Silver with Silicon Carbide in HTGR Fuel Particles. Oak Ridge National Laboratory, Tennessee, 1982.

${ }^{11}$ P. Demkowicz, K. Wright, J. Gan, and D. A. Petti, "High Temperature Interface Reactions of TiC, TiN, and $\mathrm{SiC}$ with Palladium and Rhodium," Solid State Ionics, 179, 2313-21 (2008).

${ }^{12}$ L. Y. Chen, G. W. Hunter, P. G. Neudeck, and G. Bansal, "Comparison of Interfacial and Electronic Properties of Annealed $\mathrm{Pd} / \mathrm{SiC}$ and $\mathrm{Pd} / \mathrm{SiO}_{2} / \mathrm{SiC}$ Schottky Diode Sensors," J. Vac. Sci. Technol., A, 15 [3] 1228-34 (1997).

${ }^{13}$ E. López-Honorato, P. J. Meadows, J. Tan, and P. Xiao, "Control of Stoichiometry, Microstructure and Mechanical Properties in SiC Coatings Produced by Fluidized Bed Chemical Vapor Deposition," J. Mater. Res., 23 [6] 1785-96 (2008).

${ }^{14}$ E. López-Honorato, J. Tan, P. J. Meadows, G. Marsh, and P. Xiao, “TRISO Coated Fuel Particles with Enhanced SiC Properties," J. Nucl. Mater., 392, 219-24 (2009).

${ }^{15}$ C. M. Barnes, D. W. Marshall, J. Hunn, B. L. Tomlin, and J. T. Keeley, "Results of Tests to Demonstrate a Six-Inch Diameter Coater for Production of TRISO-Coated Particles for Advanced Gas Reactor Experiments"; in 4th International Topical Meeting on High Temperature Reactor Technology, HTR2008, Washington, DC, USA, 2008.

${ }^{16}$ E. López-Honorato, P. J. Meadows, and P. Xiao, "Fluidized Bed Chemical Vapor Deposition of Pyrolytic Carbon-I. Effect of Deposition Conditions on Microstructure," Carbon, 47, 396-410 (2009).

${ }^{17}$ E. López-Honorato, P. J. Meadows, P. Xiao, G. Marsh, and T. J. Abram, "Structure and Mechanical Properties of Pyrolytic Carbon Produced by Fluidized Bed Chemical Vapor Deposition," Nucl. Eng. Des., 238, 3121-8 (2008).

${ }^{18}$ H. S. Kim and D. J. Choi, "Effect of Diluent Gases on Growth Behavior and Characteristics of Chemical Vapor Deposited Silicon Carbide Films," J. Am. Ceram. Soc., 82 [2] 331-7 (1999).

${ }^{19} \mathrm{~K}$. Bhanumurthy and R. Schmid-Fetzer, "Interface Reactions Between Silicon Carbide and Metals (Ni, Cr, Pd, Zr)," Composites A, 32, 569-74 (2001).

${ }^{20}$ A. A. Kodentsov, M. R. Rijnders, and F. J. J. Van Loo, "Periodic Pattern Formation in Solid State Reactions Related to the Kirkendall Effect," Acta Mater., 46 [18] 6521-8 (1998).

${ }^{21}$ C. R. Kao and Y. A. Chang, "A Theoretical Analysis for the Formation of Periodic Layered Structure in Ternary Diffusion Couples Involving a Displacement Type of Reactions," Acta Metall. Mater., 41 [12] 3463-72 (1993).

${ }^{22}$ I. Gutman, I. Gotman, and M. Shapiro, "Kinetics and Mechanism of Periodic Structure Formation at $\mathrm{SiO}_{2} / \mathrm{Mg}$ Interface," Acta Mater., 54, 4677-88 (2006).

${ }^{23}$ M. H. He, X. Su, F. Yin, J. Wang, and Z. Li, "Periodic Layered Structure in $\mathrm{Ni}_{3} \mathrm{Si} / \mathrm{Zn}$ Diffusion Couples," Scr. Mater., 59, 411-3 (2008).
${ }^{24}$ L. Klinger, I. Gotman, and I. Gutman, "A Switch-Over Model of Periodic Structure Formation in Ternary Diffusion Couples," Scr. Mater., 45, 1221-6 (2001).

${ }^{25}$ I. Gutman, L. Klinger, I. Gotman, and M. Shapiro, "Experimental Observation of Periodic Structure Formation in $\mathrm{SiO}_{2}-\mathrm{Mg}$ System," Scr. Mater., 45, 363-7 (2001).

${ }^{26} \mathrm{Z}$. Du, C. Guo, X. Yang, and T. Liu, "A Thermodynamic Description of the Pd-Si-C System," Intermetallics, 14, 560-9 (2006).

${ }^{27}$ L. L. Snead, T. Nozawa, Y. Katoh, T. S. Byun, S. Kondo, and D. A. Petti, "Handbook of SiC Properties for Fuel Performance Modeling," J. Nucl. Mater., 371, 329-77 (2007)

${ }^{28}$ S. J. Zinkle, V. A. Skuratov, and D. T. Hoelzer, "On the Conflicting Roles of Ionizing Radiation in Ceramics," Nucl. Instrum. Methods Phys. Res., Sect. B, 191, 758-66 (2002).

${ }^{29}$ W. Jiang, W. J. Weber, V. Shutthanandan, L. Li, and S. Thevuthasan, "Thermal and Dynamic Response of Ag Implants in Silicon Carbide," Nucl. Instrum. Methods Phys. Res., Sect. B, 219-220, 642-6 (2004)

${ }^{30}$ Y. Katoh, N. Hashimoto, S. Kondo, L. L. Snead, and A. Kohyama, "Microstructural Development in Cubic Silicon Carbide During Irradiation at Elevated Temperatures," J. Nucl. Mater., 351, 228-40 (2006).

${ }^{31}$ W. J. Kim, J. N. Park, M. S. Cho, and J. Y. Park, "Effect of Coating Temperature on Properties of SiC Layer in TRISO-Coated Particles," J. Nucl. Mater. 392, 213-8 (2009).

${ }^{32}$ H. Hirayama, T. Kawakubo, and A. Goto, "Corrosion Behavior of Silicon Carbide in $290^{\circ}$ C Water," J. Am. Ceram. Soc., 72 [11] 2049-53 (1989).

${ }^{33}$ G. Drazic, R. Forthmann, and A. Naoumidis, "Basic Studies of the Corrosion of SiC by Silicate Melts," J. Mater. Sci., 28, 2377-84 (1993).

${ }^{34}$ L. Tan, T. R. Allen, and E. Barringer, "Effect of Microstructure on the Corrosion of CVD-SiC Exposed to Supercritical Water," J. Nucl. Mater., 394, 95-101 (2009).

${ }^{35}$ W. J. Kim, H. S. Hwang, and J. Y. Park, "Corrosion Behavior of ReactionBonded Silicon Carbide Ceramics in High-Temperature Water," J. Mater. Sci. Lett., 21, 733-5 (2002).

${ }^{36}$ D. Landolt, Corrosion and Surface Chemistry of Metals. EPFL Press, Boca Raton, 2007.

${ }^{37}$ Y. Kajikawa, S. Noda, and H. Komiyama, "Preferred Orientation of Chemical Vapor Deposited Polycrystalline Silicon Carbide Films," Chem. Vap. Deposition, 8 [3] 99-104 (2002).

${ }^{38}$ D. J. Kim and D. J. Choi, "High-Temperature Corrosion Resistance of Chemically Vapor Deposited Silicon Carbide Against Hydrogen Chloride and Hydrogen Gaseous Environment," J. Am. Ceram. Soc., 79 [2] 503-6 (1996).

${ }^{39}$ D. Helary, O. Dunge, X. Bourrat, P. H. Jouneau, and F. Cellier, "EBSD Investigation of SiC for HTR Fuel Particles," J. Nucl. Mater., 350 [3] 332-5 (2006).

${ }^{40}$ L. Tan, T. R. Allen, J. D. Hunn, and J. H. Miller, "EBSD for Microstructure and Property Characterization of the SiC-Coating in TRISO Fuel Particles," J. Nucl. Mater., 372 [2-3] 400-4 (2008).

${ }^{41}$ L. C. Lim and T. Watanabe, "Fracture Toughness and Brittle-Ductile Transition Controlled by Grain Boundary Character Distribution (GBCD) in Polycrystals," Acta Metall. Mater., 38 [12] 2507-16 (1990). 